\title{
Perforation of Gastric Wall by Polymethylmethacrylate after Percutaneous Kyphoplasty: Case Report and Literature Review
}

\author{
Jun ZHANG, Hai-Yu SHAO, Shao-Nan XU, Ya-Zeng HUANG \\ Zhejiang Provincial People's Hospital, Department of Orthopedics, Hangzhou, Zhejiang, China
}

\section{ABSTRACT}

Kyphoplasty is a minimal invasive technique with a low rate of complications. To the best of our knowledge, perforation of gastric wall following kyphoplasty has not been described yet. We present a case that was operated for radical resection of esophageal carcinoma eleven years ago and who underwent kyphoplasty after a recent sixth and seventh thoracic vertebral fracture was diagnosed. Afterwards, the patient complained of dysphagia and fever. His laboratory results showed signs of inflammation. Gastroscopy showed a foreign body in the stomach. Plain radiography, computed tomography scan and positron emission computed tomography confirmed the diagnosis of perforation of the gastric wall by polymethylmethacrylate. Despite adequate antibiotic treatment, the patient died from septic multiple organ failure. Indication for kyphoplasty in patients with any history of thoracic surgery should be scrutinized rigorously. Although this kind of complication may be relatively rare, awareness of this condition will improve our response to avoid any delay in making the correct diagnosis and providing specific treatment.

KEYWORDS: Kyphoplasty, Cement leakage, Perforation of gastric wall

\section{INTRODUCTION}

\begin{abstract}
$\Lambda$ fter introduction by Galibert et al. (14), kyphoplasty and percutaneous vertebroplasty have become the most Lcommonly used minimally invasive techniques for the treatment of osteoporotic vertebral fractures and osteolytic metastases $(2,4,6,9,17,27,28)$. Complication rates are low and comprise cement leakage $(8,11,20,21,24,25)$, neurologic complications (15), pulmonary embolism (5), perforation of cardiac ventricular wall $(10,12,26)$ and subsequent fractures of adjacent vertebrae $(13,16,24)$. The purposes of this report are to present a case with perforation of gastric wall after thoracic kyphoplasty and increase awareness of possible injury following cement leakage to the anterior aspect of the spine. We have been unable to find reports of perforation of gastric wall following kyphoplasty in our literature search.
\end{abstract}

\section{CASE REPORT}

This 66-year-old man had a surgical history of radical resec- tion of esophageal carcinoma eleven years ago. He reported having suffered a fall about one month prior to his admission and described persistent back pain. The physical examination disclosed no neurological findings in the lower extremities. He has undergone kyphoplasty after a recent sixth and seventh thoracic vertebral fracture (suspected esophageal carcinoma metastases) was diagnosed by magnetic resonance imaging (MRI). Kyphoplasty was performed bipedicularly, using polymethylmethacrylate bone cement containing hydroxyapatite. On both sides, the balloons were inflated to a volume of 3.5 $\mathrm{mL}$ using visual and pressure controls. To obtain a thick liquid consistency, a total of $3 \mathrm{~mL}$ cement per side was inserted under fluoroscopic monitoring. A biopsy specimen was obtained during the procedure and demonstrated non-cancerous tissue.

This patient presented with dysphagia and fever one month after he underwent kyphoplasty and was readmitted. Emergency laboratory results were as follows: white blood cell count, $3.49 \times 10^{9} / \mathrm{L}$; C-reactive protein, $124.0 \mathrm{mg} / \mathrm{L}$; erythrocyte sedi- 
mentation rate, $80.0 \mathrm{~mm} / \mathrm{h}$; Lipopolysaccharide, $177.0 \mathrm{pg} / \mathrm{ml}$; NAP 82.0\%; NAPC 82. Other blood biochemistry tests were normal. Clinical examination on admission was unremarkable.

An unknown foreign body, about 30 centimeters from the incisors, was detected perforating the gastric wall by gastroscope (Figure 1). It was quite stiff and could not be removed. Post-operative X-Ray demonstrated cement leakage from the anterior wall of the vertebral body (Figure 2A, B). Computed

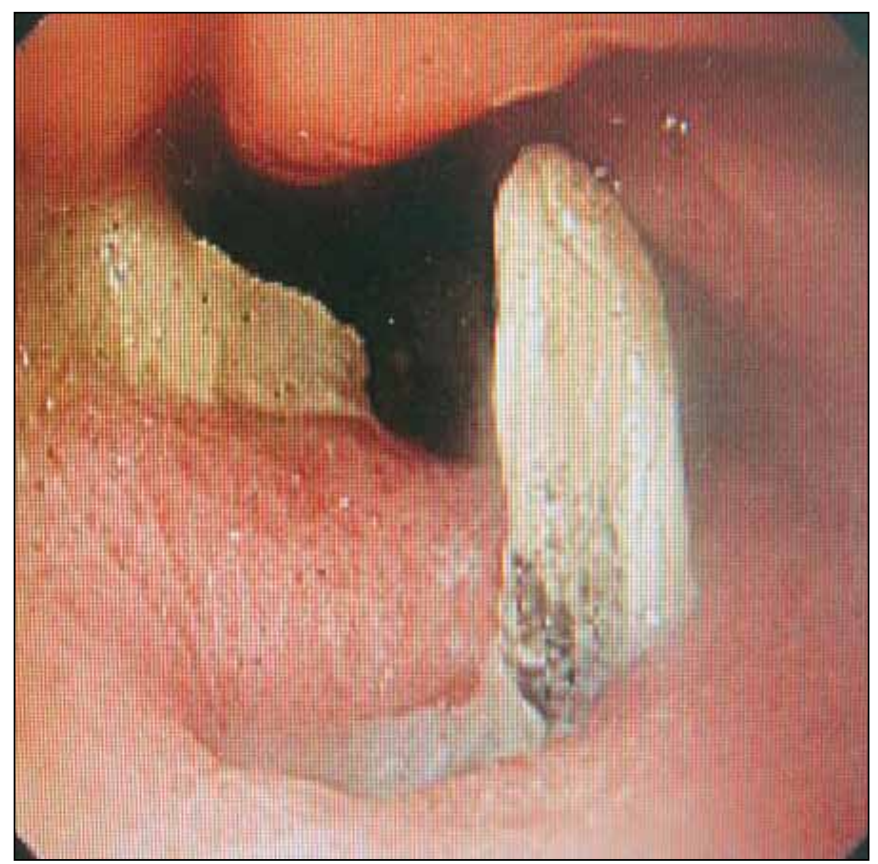

Figure 1: Gastroscopy showing a cement embolus penetrating the gastric wall. tomographic scan and positron emission computed tomography confirmed the diagnosis of perforation of gastric wall by polymethylmethacrylate (Figure 3A, B). We tried several times to remove it through a gastroscope and failed. The patient refused thoracic surgery. Despite adequate antibiotic treatment, the patient died from septic multiple organ failure.

\section{DISCUSSION}

Kyphoplasty is generally regarded as safe and efficacious for treating vertebral compression fractures, and its risks are considered to be low. Cement leakage occur more frequently in vertebroplasty (from $30 \%$ to $75 \%$ ) than kyphoplasty (from $8 \%$ to $33 \%$ ) (1). As kyphoplasty becomes more popular, our knowledge of its potential complications must also expand.

Perforation of the adjacent organs is a relatively rare complication in the literature $(10,12,26)$. In this case, the patient had a surgical history of radical resection of esophageal carcinoma eleven years ago. His gastric wall was adhering to the anterior wall of the thoracic vertebral body. It is unclear when the gastric wall perforation occurred. According to the time of his complaint, it is more likely that damage to the gastric wall occurred post-operatively due to the peristalsis of stomach.

The well-established factors that contribute to cement leakage are viscosity and the amount of injected cement $(6,7)$. Cement leakage has been shown to be usually caused by excessive cement injection (22). An experimental study has indicated that extravasation risk decreased when cement viscosity, bone pore size, bone permeability and bone porosity increased, and when the diameter of the extravasation path and viscosity of the marrow decreased (3). A relatively novel percutaneous vertebral augmentation implant, KIVA (Kiva ${ }^{\circledR}$ VCF Treatment

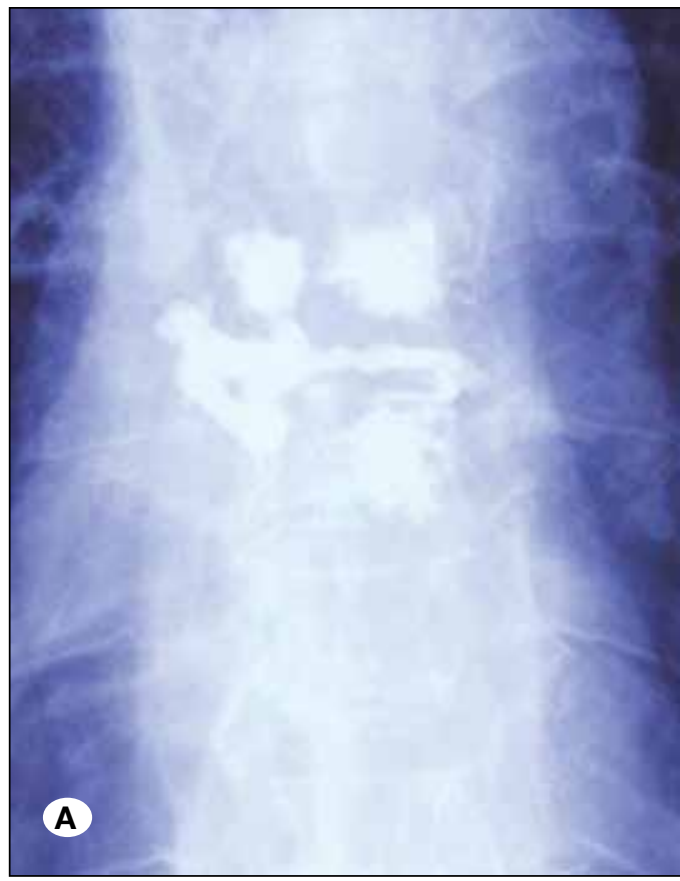



Figure 2: Post-operative X-Ray demonstrated cement leakage from the anterior wall of vertebral body. Anteroposterior view (A). Lateral view (B). 

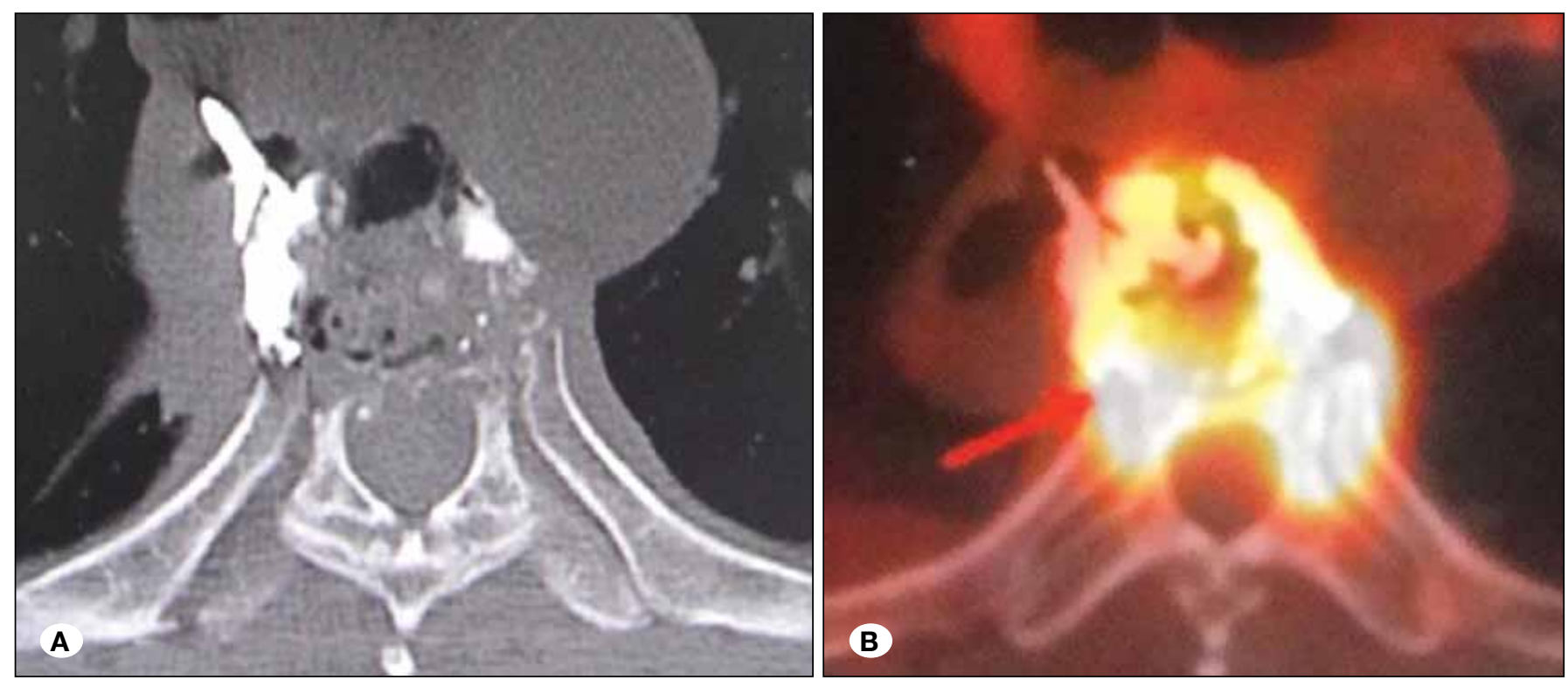

Figure 3: Computed tomography and positron emission computed tomography confirmed the diagnosis of perforation of gastric wall by polymethylmethacrylate. Computed tomography (A). Positron emission computed tomography (B).

System, Benvenue Medical, Santa Clara, CA, USA), which received CE Mark approval in December 2008, could also decrease extravasation risk due to its higher viscosity cement used compared with kyphoplasty and vertebroplasty $(18,19$, 23). The Kiva ${ }^{\circledR}$ System is a sterile, single-use device in which an external delivery handle is used to deploy the Kiva $\circledR$ implant over a nitinol coil guidewire.

\section{CONCLUSION}

Cement leakage into the digestive system after kyphoplasty is a rare complication. To the best of our knowledge, this is the first reported case of gastric wall perforation by cement leakage after kyphoplasty. Indication for kyphoplasty in patients with any history of thoracic surgery should be scrutinized rigorously. In case of post-procedural dysphagia and fever, it is mandatory to exclude esophageal or gastric wall perforation because of cement leakage. All safety measures should be undertaken regarding cement viscosity, amount, temperature, pressure and even KIVA in order to avoid cement leakage, especially for those who have a history of thoracic surgery.

\section{- ACKNOWLEDGEMENTS}

This study was supported by grants from the Zhejiang Provincial Natural Science Foundation of China (LY14H060006), Application Research of Public Technology of Science and Technology Department of Zhejiang Province (2012C33069), and Natural Scientific Research Foundation of Zhejiang Medical College (2011XZB01).

\section{- REFERENCES}

1. Agko $M$, Nazzal $M$, Jamil $T$, Castillo-Sang $M$, Clark $P$, Kasper G: Prevention of cardiopulmonary embolization of polymethylmethacrylate cement fragment after kyphoplasty with insertion of inferior vena cava filter. J Vasc Surg 51: 210213, 2010

2. Barr JD, Barr MS, Lemley TJ, McCann RM: Percutaneous vertebroplasty for pain relief and spinal stabilization. Spine 25: 923-928, 2000

3. Bohner M, Gasser B, Baroud G, Heini P: Theoretical and experimental model to describe the injection of a polymethylmethacrylate cement into a porous structure. Biomaterials 24: 2721-2730, 2003

4. Cagli S, Isik HS, Zileli M: Vertebroplasty and kyphoplasty under local anesthesia: Review of 91 patients. Turk Neurosurg 20: 464-469, 2010

5. Choe DH, Marom EM, Ahrar K, Truong MT, Madewell JE: Pulmonary embolism of polymethyl methacrylate during percutaneous vertebroplasty and kyphoplasty. AJR Am J Roentgenol 183: 1097-1102, 2004

6. Cotten A, Boutry N, Cortet B, Assaker R, Demondion X, Leblond D, Chastanet $P$, Duquesnoy $B$, Deramond $H$ : Percutaneous vertebroplasty: state of the art. Radiographics 18: 311-320, 1998

7. Cotten A, Dewatre F, Cortet B, Assaker R, Leblond D, Duquesnoy B, Chastanet P, Clarisse J: Percutaneous vertebroplasty for osteolytic metastases and myeloma: effects of the percentage of lesion filling and the leakage of methyl methacrylate at clinical follow-up. Radiology 200: 525530, 1996

8. Coumans JV, Reinhardt MK, Lieberman IH: Kyphoplasty for vertebral compression fractures: 1-year clinical outcomes from a prospective study. J Neurosurg 99:44-50, 2003 
9. Deramond H, Galibert P, Depriester-Debussche C: Percutaneous intraosseous injections in the palliative treatment of bone metastases. Bull Cancer 80: 36-40, 1993

10. Dreger H, Treskatsch S, Lembcke A, Grubitzsch H, Knebel F, Laule M: Perforation of the right ventricle by bone cement: $A$ rare complication of kyphoplasty. Eur Heart J 34:1203, 2013

11. Dudeney S, Lieberman IH, Reinhardt MK, Hussein M: Kyphoplasty in the treatment of osteolytic vertebral compression fractures as a result of multiple myeloma. J Clin Oncol 20: 2382-2387, 2002

12. Farahvar A, Dubensky D, Bakos R: Perforation of the right cardiac ventricular wall by polymethylmethacrylate after lumbar kyphoplasty. J Neurosurg Spine 11: 487-491, 2009

13. Fribourg D, Tang C, Sra P, Delamarter R, Bae H: Incidence of subsequent vertebral fracture after kyphoplasty. Spine 29: 2270-2276, 2004

14. Galibert P, Deramond H, Rosat P, Le Gars D: Preliminary note on the treatment of vertebral angioma by percutaneous acrylic vertebroplasty. Neurochirurgie 33:166-168, 1987

15. Garfin SR, Yuan HA, Reiley MA: New technologies in spine: Kyphoplasty and vertebroplasty for the treatment of painful osteoporotic compression fractures. Spine 26:1511-1515, 2001

16. Harrop JS, Prpa B, Reinhardt MK, Lieberman I: Primary and secondary osteoporosis' incidence of subsequent vertebral compression fractures after kyphoplasty. Spine 29:21202125, 2004

17. Jensen ME, Evans AJ, Mathis JM, Kallmes DF, Cloft HJ, Dion JE: Percutaneous polymethylmethacrylate vertebroplasty in the treatment of osteoporotic vertebral body compression fractures: Technical aspects. AJNR Am J Neuroradiol 18: 1897-1904, 1997

18. Korovessis P, Repantis T, Miller LE, Block JE: Initial clinical experience with a novel vertebral augmentation system for treatment of symptomatic vertebral compression fractures: A case series of 26 consecutive patients. BMC Musculoskelet Disord 12: 206, 2011
19. Korovessis P, Vardakastanis K, Repantis T, Vitsas V: Balloon kyphoplasty versus KIVA vertebral augmentation-comparison of 2 techniques for osteoporotic vertebral body fractures: A prospective randomized study. Spine 38: 292-299, 2013

20. Ledlie JT, Renfro M: Balloon kyphoplasty: One-year outcomes in vertebral body height restoration, chronic pain, and activity levels. J Neurosurg 98:36-42, 2003

21. Lieberman IH, Dudeney S, Reinhardt MK, Bell G: Initial outcome and efficacy of "kyphoplasty" in the treatment of painful osteoporotic vertebral compression fractures. Spine 26: 1631-1638, 2001

22. Martin JB, Jean B, Sugiu K, San Millan Ruiz D, Piotin M, Murphy K, Rufenacht B, Muster M, Rufenacht DA: Vertebroplasty: Clinical experience and follow-up results. Bone 25: 11S-15S, 1999

23. Panagiotis I, Panagiotis K, Vasilios V: PMMA embolization to the left dorsal foot artery during percutaneous vertebroplasty for spinal metastases. Eur Spine J 23: 187-191, 2013

24. Phillips FM, Ho E, Campbell-Hupp M, McNally T, Todd Wetzel F, Gupta P: Early radiographic and clinical results of balloon kyphoplasty for the treatment of osteoporotic vertebral compression fractures. Spine 28: 2260-2265, 2003

25. Rhyne A 3rd, Banit D, Laxer E, Odum S, Nussman D: Kyphoplasty: Report of eighty-two thoracolumbar osteoporotic vertebral fractures. J Orthop Trauma 18: 294-299, 2004

26. Tran I, Gerckens U, Remig J, Zintl G, Textor J: First report of a life-threatening cardiac complication after percutaneous balloon kyphoplasty. Spine 38: E316-318, 2013

27. Watts NB, Harris ST, Genant HK: Treatment of painful osteoporotic vertebral fractures with percutaneous vertebroplasty or kyphoplasty. Osteoporos Int 12: 429-437, 2001

28. Weill A, Chiras J, Simon JM, Rose M, Sola-Martinez T, Enkaoua E: Spinal metastases: Indications for and results of percutaneous injection of acrylic surgical cement. Radiology 199: 241-247, 1996 